\title{
Announcement
}

\section{International Meeting on Hormonal Therapy of Prostatic Diseases: Basic and Clinical Aspects} Milano, Italy, May 21-24, 1986

An International Symposium on 'Hormonal Therapy of Prostatic Diseases: Basic and Clinical Aspects’ will be held at the Michelangelo Hotel (Milano, Italy) from May 21 to May 24, 1986. The meeting will be planned by an International Scientific Committee formed by: A. Bartke (USA), N. Bruchowsky (Canada), J. Geller (USA), M. Motta (Italy), J. Robinson (UK), M. Serio (Italy), K.D. Voigt (Germany).

The program will include invited lecturers as well as sessions of free communications and/or poster presentations on the following topics: The normal prostate: morphological, biochemical and hor-

monal aspects; The pathological prostate (BPH, carcinoma, etc.): morphological, biochemical and hormonal aspects; Therapeutic approaches in prostatic diseases (animal and human studies).

For further information regarding the program, please contact the Scientific Secretaries: M. Motta and M. Serio, Department of Endocrinology, University of Milano, 21, Via Andrea del Sarto, 20129 Milano, Italy, Tel. $02-7385351$.

For registration, travel and logistic information, please contact the Organizing Secretariat: O.I.C., 11, Largo Corsia dei Servi, 20121 Milano, Italy, Tel. 02 - $708357 / 7084$ 19. 